\title{
Treinamento de Habilidades Sociais Educativas para Pais de Crianças com Problemas de Comportamento
}

\section{Training Parent Social Skills for Families of Children with Behavior Problems}

\author{
Maria Isabel Santos Pinheiro ${ }^{\mathrm{a}, *}$, Vitor Geraldi Haase ${ }^{\mathrm{a}}$, Almir Del Prette ${ }^{\mathrm{b}}$, \\ Claret Luiz Dias Amarante ${ }^{a}$, Zilda Aparecida Pereira Del Prette ${ }^{b}$ \\ ${ }^{a}$ Universidade Federal de Minas Gerais, Belo Horizonte, Brasil, ${ }^{b}$ Universidade Federal de São Carlos, São Carlos, Brasil
}

\begin{abstract}
Resumo
Este artigo descreve um programa de Treinamento de Habilidades Sociais para pais de crianças com problemas de comportamento. O programa, com duração de 11 semanas, apresentou, por meio de passos semanais seqüenciados, princípios da análise do comportamento para a prática disciplinar não-coerciva e modelos de habilidades sociais educativas para pais, com tarefas semanais de observar o comportamento do filho, estabelecer condições de aprendizagem e desempenho de comportamentos desejáveis (empatia, seguimento de instruções, independência etc.), expressão afetiva entre outros. Participaram do programa 32 mães e dois pais, com avaliações pré e pós-intervenção por meio de questionários de auto-relato e entrevistas. Os resultados mostraram redução significativa na freqüência e severidade de comportamentos importunos e/ou indisciplinados, conforme avaliação dos pais. Concluiu-se que o enfoque de habilidades sociais educativas para pais pode contribuir positivamente para o desenvolvimento de práticas disciplinares não-coercivas junto a essa clientela.

Palavras-Chave: Treinamento de pais; treinamento de habilidades sociais; modificação do comportamento; disciplina não-coerciva; comportamentos externalizantes; educação infantil.
\end{abstract}

\begin{abstract}
This paper describes a Parental Social Skills Program aimed to reduce children behavior problems. The program, lasting 11 weeks, was implemented by means of weekly sequential steps starting with behavior analysis principles for parents to practice a non-coercitive discipline and to learn, models of parental social skills. Parents received weekly home assignments to observe the children's behavior, to establish favorable learning conditions for children to behave in desirable ways (empathy, compliance, independence etc.) and to adequately express emotions. Thirty-two mothers and two fathers participated in the program. Self-report questionnaires and open interviews in the pre-and post-intervention phases were used to assess the program's efficacy. Results showed significant reduction in the frequency and severity of disruptive and/or noncompliant behavior, as assessed by the parents. In conclusion, the approach of educational social abilities for parents may contribute positively to the development of non-coercitive disciplinary practices.

Keywords: Parent training; social skills training; behavior modification; non-coercitive discipline;

externalizing behaviors; family, childhood education.
\end{abstract}

A importância da estrutura familiar e do estilo de criação para o desenvolvimento das crianças têm sido ressaltada em diversos estudos (Loeber \& Hay, 1997, Patterson, 1986). $\mathrm{O}$ reconhecimento destes fatores, somado à dificuldade dos pais para conciliar os problemas cotidianos com a criação de seus filhos inspiraram a elaboração de programas específicos, com o objetivo de capacitar os pais na promoção de um desenvolvimento mais adaptativo das crianças com dificuldades de comportamento (Barkley, 1997; McMahon, 1999).

De acordo com algumas abordagens contemporâneas, o desenvolvimento individual está relacionado a fatores

\footnotetext{
Endereço para correspondência: Av. Francisco Sales, 1614/1801, Santa Efigênia Belo Horizonte, MG, 30150-22 1. Fone (31) 3282 7828. Alameda das Ameixeiras, 60 - Parque Faber, São Carlos, SP, 13561-358. E-mail: isabel@pib.com.br Os autores agradecem às alunas do Curso de Psicologia da Universidade Federal de Minas Gerais - UFMG, Clicie A. P. Lourenço e Paula P. Libório, pela inestimável colaboração, e às agências de fomento FAPEMIG, PIBIC/UFMG.
}

genético-individuais, experiências individuais precoces e, principalmente, à observação de modelos (Dodge, 1993). O temperamento impulsivo, desafiador e intolerante a frustrações, associado a déficits cognitivos e inabilidade no manejo social podem constituir um quadro de características de comportamentos inadequados, caso a criança obtenha ganhos com a não realização de tarefas, acesso a privilégios e atenção. Esses comportamentos desadaptativos estão relacionados às características das crianças, às práticas parentais, à história de interação familiar e à situação escolar.

Algumas famílias são tão disfuncionais que os pais, simplesmente não conseguem cumprir seu papel de educar os filhos (Haase, Käppler \& Schaefer, 2000). Essas famílias, de acordo com a tipologia de Baumrind (1996), são chamadas de negligentes, com pouca ou nenhuma autoridade ou envolvimento com a criança. Alguns pais defendem a idéia de que é imprescindível disciplinar os filhos e que, se não o 
fizerem de modo severo, as crianças não internalizarão os valores sociais sancionados pela comunidade em que vivem. Este é o estilo "antigo" ou autoritário. Um estilo alternativo preconiza o envolvimento com modelos positivos disponíveis para que as crianças aprendam o certo e o errado. Esse é o estilo indulgente ou "laissez faire", em que os pais adotam uma atitude supostamente "liberal" e negligenciam a necessidade de monitorar o comportamento dos filhos. Uma espécie de contrapeso a estes dois extremos polarizados é o modelo eficiente, "authoritative" ou democrático-recíproco (Gomide, 2003; Oliveira et al., 2002), em que a disciplina é construída a partir de uma base de confiança mútua e os pais adotam um estilo mais contratual, em que as normas e regras são explicadas e negociadas com a criança sob a forma de combinados. Apesar de inúmeros estudos longitudinais (ver revisão em Collins, Maccoby, Steinberg, Hetherington, \& Bornstein, 2000) demonstrarem que o estilo democrático-recíproco ou competente é o que se correlaciona com os resultados mais positivos, do ponto de vista do desenvolvimento da criança, esse é o método mais raramente empregado e o que exige maior preparo e disposição por parte dos pais e educadores. Algumas pesquisas brasileiras com adolescentes (Costa, Teixeira \& Gomes, 2000; Weber, Prado, Viezzer \& Brandenburg, 2004) encontraram, entretanto, resultados diferentes, situando o estilo democrático-recíproco como o segundo mais utilizado pelos pais, juntamente com o estilo negligente.

A escola completa o quadro das influências mais significativas sobre o comportamento infantil e contribui de diversos modos para a formação do indivíduo por meio de desenvolvimento de comportamentos, habilidades e valores etc. Os dois principais ambientes na vida da criança (o doméstico e o escolar) concorrem para que o resultado final seja percebido pelos pais e educadores como comportamento adaptativo ou desadaptativo, com o "bom" comportamento ou "mau" comportamento.

As inúmeras dificuldades enfrentadas e a crescente preocupação de pais e educadores com o processo educativo das crianças motivaram, em muitos países, a criação de programas direcionados aos pais. Esses programas os ensinam a serem "terapeutas comportamentais" de si e dos próprios filhos e vêm sendo utilizados, com sucesso, há mais de 25 anos (Barkley, 1997; McMahon, 1999). O treinamento de pais tem sido aplicado com diversos objetivos, entre eles o tratamento de problemas explícitos de comportamento (birras, agressões, desobediência excessiva etc.). Por exemplo, Haase, Freitas, Natale e Pinheiro (2002) adaptaram um programa de treinamento para pais objetivando estimular a interação social em uma criança com epilepsia. A idéia de introduzir este modelo triádico, em que os pais se transformam em mediadores, tem base nos conceitos já discutidos, de que grande parte dos comportamentos inadequados das crianças se manifesta e é mantida devido aos déficits de habilidades sociais apresentados pelos próprios pais para manejar os comportamentos de seus filhos.

Dessa forma, qualquer modificação efetiva e duradoura dos comportamentos da criança pressupõe uma mudança prévia na forma com que os cuidadores lidam com ela. Por isso, alguns programas de treinamento introduzem, de modo didático, os fundamentos da análise do comportamento aplicada, instruindo os pais a motivarem os filhos a se comportarem bem e supervisionando-os na aplicação de técnicas de incentivo, de atenção ao bom desempenho e de retirada de atenção quando a criança não se comporta da maneira combinada. Tais programas são indicados para pais com crianças a partir de três anos de idade até próximo à entrada na adolescência (Barkley, 1997).

Pesquisas conduzidas por diversos autores (Patterson, Reid \& Dishion, 1992; Rutter, 1997; Simons, Chão, Conger \& Elder, 2001) indicam que o comportamento anti-social parece ser a evolução de uma característica que se desenvolve cedo na vida e, mesmo quando não se mantém na adolescência e na fase adulta, pode ter consequiências negativas sobre o desenvolvimento do jovem. Esses autores argumentam que crianças agressivas e opositivas vivem em situação de risco, podendo desenvolver comportamentos delinqüentes na adolescência, pois freqüentemente são educadas em ambiente em que as práticas parentais são inadequadas.

Um dos primeiros fatores de risco considerados diz respeito aos déficits em habilidades cognitivas e sociais disponíveis no repertório comportamental do indivíduo (A. Del Prette \& Z. A. P. Del Prette, 2003; Haase, Käppler \& Schaefer, 2000). O termo habilidades sociais remete a uma área da Psicologia e se refere à existência de diferentes classes de comportamentos sociais no repertório do indivíduo para lidar de maneira adequada com demandas das situações interpessoais (Z. A. P. Del Prette \& A. Del Prette, 1999). Quando a falta de habilidades sociais é crítica, as relações sociais podem se tornar restritas e conflitivas, interferindo de maneira negativa no grupo em que o indivíduo está inserido, e, sobretudo, em sua saúde psicológica (A. Del Prette \& Z. A. P. Del Prette, 2001; Z. A. P. Del Prette \& A. Del Prette, 2005).

A forma de interação entre pais e filhos constitui fator relevante que interfere no repertório social dos filhos. Bolsoni-Silva, Del Prette e Oishi (2003) identificaram algumas habilidades sociais educativas dos pais como condição importante para um desenvolvimento adequado do repertório social dos filhos. Quando os pais apresentavam melhor repertório dessas habilidades, os filhos apresentaram maior freqüência de comportamentos adequados; ao contrário, quando os pais apresentaram repertório pobre dessas habilidades, os filhos também apresentaram déficits interpessoais e comportamentos desadaptativos.

Um fator de risco significativo para o desenvolvimento de comportamentos desadaptativos está relacionado à exposição a modelos agressivos, que são reforçados, tanto positiva quanto negativamente, durante as experiências sociais iniciais. O resultado pode ser o surgimento de ciclos de interações coercivas na família (Patterson, 1986; Patterson, DeBaryshe \& Ramsey, 1989), que podem escalar para uma verdadeira transmissão intergeracional de ciclos de coerção (Dodge, Bates \& Pettit, 1990). O comportamento do 
terapeuta, nos programas de treinamento cognitivocomportamental, pode constituir um modelo alternativo, na medida em que procura ensinar formas não-coercivas de interação social.

O repertório cognitivo-comportamental deficiente, no que se refere às habilidades sociais, pode resultar, em parte, de características temperamentais individuais, mas, certamente, a experiência individual de relacionamentos predatórios e pouco gratificantes contribui para que o indivíduo desenvolva determinados esquemas cognitivos relacionados a expectativas hostis em relação ao outro. O histórico de experiências fracassadas de relacionamentos interpessoais contribui para o desenvolvimento insuficiente de alguns aspectos do autoconceito, tais como a auto-estima e a autoeficácia. Os comportamentos agressivos, excetuando-se a agressão predatória ou psicopática, podem ser, em grande parte, pró-ativos, ou seja, representam uma defesa do indivíduo diante da possibilidade de uma agressão percebida como iminente (Petermann \& Petermann, 1997).

A deficiência na capacidade de prever as conseqüências das próprias ações e a incapacidade de assumir a perspectiva do outro completam o quadro de fatores individuais relacionados ao comportamento agressivo. As evidências provenientes da terapia de família (Becvar \& Becvar, 1999; Nichols $\&$ Schwartz, 1998) indicam, entretanto, que essa dificuldade pode não resultar exclusivamente de deficiências intraindividuais, constituindo-se mesmo em um fator quase que normativo do sistema familiar.

O programa de Treinamento de Pais em Habilidades Sociais (TP-HS) procura enfatizar as diferenças de perspectiva de pais e crianças, determinadas principalmente pelos estágios e tarefas específicas a cada fase de desenvolvimento. Alguns pais ficam desconcertados ao se confrontarem com uma alternativa diferente, em que lhes é proposto o desafio de modificarem antes o seu próprio comportamento com o intuito de modificar o comportamento de sua criança. Nessas circunstâncias, o terapeuta procura intervir pedagogicamente, demonstrando para os pais a relação que existe entre o seu comportamento e o comportamento da criança.

Este artigo descreve a adaptação e a aplicação de um Programa de Treinamento de Pais em Habilidades Sociais (PTP-HS), com vistas à capacitação de famílias de baixa renda para o manejo não-coercivo das dificuldades disciplinares apresentadas por seus filhos.

\section{Método \\ Contexto e Participantes da Pesquisa}

O programa TP-HS foi implementado em uma Escola Municipal de Belo Horizonte (MG), que atendia crianças e adultos e possuía cerca de 650 alunos. No período diurno funcionam as quatro primeiras séries do Ensino Fundamental e no período noturno Cursos de Ensino para Jovens e Adultos. A grande maioria dos alunos reside em um aglomerado residencial próximo a escola e pertence a classes socioeconômica consideradas de risco.
A amostra inicial contou com 55 pais, distribuídos em um total de 4 grupos com aproximadamente 14 participantes cada um. Destes, 34 participaram até o final do programa, sendo 32 mães e somente 2 pais, com idade média de 35,16 anos $(\mathrm{dp}=10,52)$ e $73,5 \%$ com escolaridade inferior ao Ensino Fundamental. A idade média dos filhos era 8,84 $(\mathrm{dp}=2,05)$ sendo $61 \%$ do sexo masculino. A freqüência de indivíduos provenientes de matrimônios juridicamente formalizados foi igual a $51,5 \%$, com média de idade de 35,57 anos $(\mathrm{dp}=10,52)$.

\section{O Programa de Intervenção}

O TP-HS foi desenvolvido a partir de uma experiência inicial com a adaptação do modelo de Barkley (1997) de treinamento de pais em duas favelas da região metropolitana de Belo Horizonte (Käppler et al., 2003). Esse Treinamento de Pais em Habilidades Sociais (TP-HS) teve, como objetivo, orientar os participantes, de forma didática, sobre os fundamentos da análise aplicada do comportamento, instruí-los quanto à necessidade de motivar seus filhos a se comportarem bem, identificar determinantes dos comportamentos desadaptativos dos filhos e aplicar, no dia-a-dia, alguns dos procedimentos básicos de modificação de comportamento.

O programa baseia-se no pressuposto de que as crianças precisam ser reforçadas de modo freqüente, contingente, intenso, diferenciado e sistemático. Ele propõe uma mudança de perspectiva e o aumento do repertório de habilidades sociais dos pais para a interação com as crianças. Procura, também, atender as queixas sobre os problemas comportamentais infantis utilizando os princípios do Treinamento de Habilidades Sociais (THS) com o objetivo de desenvolver, nas crianças, comportamentos pró-sociais e a valorizar as interações e relações sociais. O programa utilizou procedimentos derivados da área do THS (A. Del Prette \& Z. A. P. Del Prette, 2001; Z. A. P. Del Prette \& A. Del Prette, 1999, 2005) e foi construído com base na definição de habilidades sociais educativas de A. Del Prette e Z. A. P. Del Prette (2001 p. 95): "aquelas intencionalmente voltadas para a promoção do desenvolvimento e aprendizagem do outro, em situação formal ou informal". O programa TPHS, descrito em detalhe em Pinheiro, Del Prette e Haase (2002), foi aplicado de forma integral.

Os encontros semanais aconteceram em uma sala disponibilizada pela escola, com início às 19:30 horas, tendo uma duração aproximada de uma hora e trinta minutos. O primeiro encontro foi destinado à apresentação dos participantes, do terapeuta e auxiliares de pesquisa, bem como para informes e avaliações diagnósticas pré-treinamento. A cada encontro foram sorteadas pequenas prendas e, a cada presença, os pais recebiam pontos para participarem de um sorteio final. Todos os encontros foram encerrados com um pequeno lanche.

A estrutura de cada um das sessões semanais foi organizada em três etapas. Na primeira etapa, eram verificadas e discutidas as tarefas propostas e realizadas pelos pais na semana anterior. Queixas de dúvidas, dificuldades, falhas e 
referências a sucessos eram analisadas pelo grupo, com mediação do terapeuta. Na segunda etapa, apresentava-se o "passo" da sessão conforme a seqüência pré-estabelecida, incentivando-se os pais a relatarem suas dificuldades e acertos. Nesta etapa, além da instrução, recorria-se a procedimentos de ensaio comportamental como prática efetiva para fortalecer a aprendizagem e facilitar a generalização. $\mathrm{Na}$ terceira e última etapa, explicitava-se a nova tarefa a ser realizada no decorrer da semana. Ao final da sessão, serviase lanche, procedendo-se a sorteios de brindes que facilitavam a interação entre os participantes.

A partir da segunda sessão, foram realizadas as etapas de intervenção, propriamente ditas, cuja temática foi organizada em nove "passos", um a cada encontro semanal, que são descritos a seguir:

\section{Passo 1 - Por que as crianças se comportam mal?}

Este passo tem como objetivo desenvolver a compreensão dos pais sobre os fatores que influenciam o comportamento da criança, como, por exemplo, características comportamentais de cada pessoa na interação. Além disso, é realçada a importância da observação das conseqüências de comportamentos desadaptativos e pró-sociais na família. Utiliza-se vivências para os pais identificarem comportamentos em desacordo com o esperado ou combinado com os filhos e como esses comportamentos são controlados pela atenção que recebem, mesmo quando a punição é utilizada.

\section{Passo 2 - Preste atenção no bom comportamento de seu filho.}

O objetivo deste passo é treinar os pais para diminuir a atenção sobre certos comportamentos e aumentar o uso de uma forma mais efetiva de atendimento e apreciação comportamental. Espera-se que os pais aprendam a prestar atenção no bom comportamento do filho, elogiando-o e valorizando-o. Na sequiência, é ensinada a técnica do "recreio especial", que contribui para descontrair o ambiente na família e aumentar o envolvimento dos pais com a criança motivando-a a cooperar com eles. Por meio de recursos didáticos como vinhetas (trechos filmados), demonstra-se que certas situações criam demandas para comportamentos interpessoais positivos, sendo "naturalmente" reforçadores para todos.

\section{Passo 3-Aumentando a brincadeira independente.}

Os pais são estimulados, neste passo, a participar de ensaios comportamentais, visando o monitoramento das atividades independentes da criança. São criadas situações de desempenho de papéis, em que os pais aprendem a elogiar a criança quando ela brinca independentemente. Além de conseqüenciar positivamente o desempenho das crianças, é solicitado que os pais ampliem, gradativamente, os episódios de brincadeira independente das crianças. Quando alguns pais apresentam dificuldade, o terapeuta apresenta modelo ou solicita a participação de outros pais para isso. Também foram apresentadas vinhetas de interação pais-filhos.
Passo 4 - Prestando atenção no comportamento de seguir instruções.

Neste passo, procura-se orientar os pais a dar instruções corretas aos filhos. Para isso, eles devem apresentar instruções curtas e de fácil execução e, em seguida ao seguimento, valorizar o desempenho da criança. São realizados vários exercícios em pequenos grupos e, ao término, cada grupo relata sua atividade aos demais. Algumas das habilidades fortalecidas com esse procedimento, como as de observar e de descrever, contribuem para aumentar a qualidade das solicitações feitas pelos pais aos filhos e, também, para que estes relatem, para a criança, como ela se comporta. Ao final utiliza-se o recurso de vídeo com os pais observando e relatando as interações filmadas.

\section{Passo 5-Ensinando a "ler" o ambiente social.}

O eixo central desta sessão é a aprendizagem de leitura do ambiente social. Este passo complementa o treino de observação da sessão anterior, com outras habilidades. Cada participante observa, durante algum tempo, um ou mais colegas de grupo em interação, relatando em seguida o que viu e sendo conseqüenciado positivamente pelo terapeuta ou pelos demais sob mediação do terapeuta. $\mathrm{Na}$ fase seguinte, os pais descrevem os desempenhos de maneira a identificar antecedentes e consequientes presentes em episódios de interação. Na terceira fase são criados exercícios que possibilitam a identificação, interpretação dos comportamentos não-verbais (Z. A. P. Del Prette \& A. Del Prette, 1999) e inferir possíveis normas presentes nas situações sociais. Essas habilidades recebem a denominação de leitura ou decodificação do ambiente social.

\section{Passo 6-Facilitando a empatia.}

Enfatizam-se, nesse passo, a aprendizagem do conceito de empatia e a compreensão de sua importância para relacionamentos saudáveis, apresentando-se exemplos do cotidiano: uma mãe que percebe que seu filho está com algum problema e o aborda sutilmente sobre isso, facilitando que a criança relate sua dificuldade; uma criança que observa os múltiplos afazeres dos pais e expressa compreensão, oferecendo-se para auxiliá-los nessas tarefas. Os pais são treinados para: (a) prestar atenção aos sinais que a criança emite quando está vivenciando algum problema (mudança na fisionomia, postura, fala etc.); (b) ouvir de maneira atentiva o que a criança tem a dizer; colocando-se no lugar da criança oferecer modelo de comportamento empático; (c) expressar verbalmente compreensão e apoio; (d) conseqüenciar positivamente as manifestações empáticas da criança; (e) oferecer modelo de comportamento empático no ambiente doméstico no relacionamento com o cônjuge.

\section{Passo 7-Melhorando o comportamento na escola.}

Considerando as aprendizagens anteriores, nesta fase do treinamento, explicita-se a importância do trabalho colaborativo entre os pais e as professoras. Os pais são orientados para monitorar as tarefas escolares, incluindo-se 
uma estratégia de verificação e ajuda sobre: (a) atividades realizadas na escola (assunto e ensino em classe e brincadeiras no recreio); (b) identificação da tarefa escolar do dia; (c) cumprimento de horário da tarefa (preferencialmente antes das atividades livres); (d) realização da tarefa (inspeção de cadernos e outros materiais). Os pais são instruídos a comunicar esse monitoramento aos professores, aumentando a probabilidade de maior atenção dispensada à criança na sala de aula, o que pode fortalecer a parceria entre família e escola.

\section{Passo 8-Representação de papéis.}

Este passo apresenta, de maneira simplificada, o modelo da teoria de papéis, segundo a qual o comportamento social depende, em grande parte, da compreensão do próprio papel e do papel do outro na relação social. $\mathrm{O}$ treinamento dessa habilidade é realizado por meio de ensaios comportamentais e role play. Esses procedimentos são utilizados em vivências, adaptadas de A. Del Prette e Z. A. P. Del Prette (2001) - "Vivendo o papel do outro", "Avanço no tempo" e "Regressão no tempo" - que levam os pais a experimentarem outros papéis, por exemplo, o dos filhos. A situação de vivência permite que sejam exercitadas outras habilidades como as de feedback, elogio, observação e descrição de desempenho, comunicação empática etc.

\section{Passo 9-Desenvolvendo a capacidade de se expressar.}

São introduzidas, nesta seqüência, informações sobre assertividade, com ênfase no exercício dos próprios direitos e na expressão de pensamentos, sentimentos e crenças. Explicitam-se as diferenças entre comportamento passivo, agressivo e assertivo, em suas dimensões verbais (conteúdo, tipo e ocasião) e não verbais (contato visual e gestualidade) Acrescenta-se, também, explicações sobre a correspondência entre direitos e deveres. As orientações são desenvolvidas no sentido de utilizarem ou promoverem contingências ambientais favorecedoras para a aquisição, o fortalecimento e/ou a manutenção de comportamentos assertivos. Adicionalmente, discute-se com os participantes as vantagens e desvantagens da assertividade no contex to familiar.

$\mathrm{Na}$ semana seguinte ao último passo, foi realizado um encontro festivo, dividido em duas partes. $\mathrm{Na}$ primeira, o terapeuta fez breves considerações incentivando os pais a continuarem utilizando os procedimentos que aprenderam. Em seguida, aplicou os questionários de pós-teste e realizou entrevistas individuais gravadas. Ao final, serviu-se um lanche, com sorteio de lembranças para os participantes, encerrando-se então o programa.

\section{Instrumentos}

A eficácia dos procedimentos de intervenção foi avaliada por meio de inventários e questionários sobre os comportamentos das crianças, aplicados junto a pais e professores antes e depois da intervenção. Ao término do programa foram também realizadas entrevistas de avaliação e aproveitamento com os pais.

\section{Informações sobre a família e a criança (Barkley, 1997).}

Este questionário coleta, junto aos pais, de informações sobre a situação socioeconômica, composição familiar e endereço para correspondência.

\section{Questionário de Situações Domésticas (QSD, de Barkley, 1997).}

Tem como objetivo identificar as diferentes situações, nas quais a criança apresenta problemas em casa, com indicação da quantidade e severidade dos comportamentos desafiantes, opositivos e agressivos da criança. As normas existentes para o Questionário de Situações Domésticas são americanas, para crianças de 4 a 11 anos. Sobre a quantidade de situações problemáticas, as médias normativas variam de 3,1 a 4,1 para meninos e de 2,2 a 3,4 para meninas. Sobre a severidade, o intervalo normativo para crianças do sexo masculino é de 1,7 a 2,0 e para as crianças do sexo feminino de 1,3 a 1,6.

\section{Inventário de Comportamentos Inoportunos (QCI, de Barkley, 1997).}

Quantifica a freqüência de comportamentos inadequados da criança, conforme indicação dos pais sobre a freqüência com que seus filhos apresentam estes comportamentos em uma escala de quatro pontos: 3 (muito freqüentemente), 2 (freqüentemente), 1 (de vez em quando), o (nunca ou raramente).

\section{Material para a intervenção.}

Além dos instrumentos já referidos, foram utilizados, para a intervenção: uma TV e aparelho de vídeo-cassete, para apresentação de vinhetas sobre interações mãe-filha, utilizadas como modelos nos passos 2, 3 e 4 do programa; banners (0,50mm X 0,90mm), com desenhos representativos do conjunto do programa e de cada um dos passos; gravador para registro de depoimentos orais; pictogramas relativos ao passo 5; carimbos para monitorização de comportamentos em sala de aula; pequenas prendas utilizadas em sorteios para os pais e comestíveis para lanche oferecido em cada sessão. Além disso, foi confeccionada uma cartilha para orientar os pais em casa.

\section{Procedimento de Coleta de Dados}

Para compor o grupo de participantes da intervenção, a disponibilidade de realização do TP-HS foi transmitida em comunicados veiculados por uma rádio comunitária, a Rádio Favela, e durante reuniões de rotina escolar por meio de cartas-convite. A participação no programa foi condicionada à assinatura de um Termo de Consentimento Livre e Esclarecido, após leitura da carta-convite e esclarecimento de dúvidas. O projeto foi aprovado pelo Comitê de Ética em Pesquisa da UFMG. Para evitar outras interferências sobre a intervenção, as professoras não foram informadas sobre quais de seus alunos tinham pais participantes no programa, sendo solicitado que respondessem os questionários sobre grande parte de seus alunos. 
Para a coleta de dados, alunos graduandos em Psicologia pela UFMG, previamente treinados, auxiliaram os pais que responderam, de forma individual, os questionários e inventários. Para isso, cada família elegeu um filho como foco de atenção naquele programa e que foi objeto dessa avaliação. Essa escolha não impedia que os procedimentos práticos executados em casa fossem utilizados também com os demais filhos, o que, aliás, esperava-se que ocorresse. Após o nono passo um novo encontro foi realizado para avaliação pós-treinamento, nos mesmos moldes da primeira.

\section{Tratamento dos Dados}

As respostas aos diferentes instrumentos de relato lápispapel foram organizadas em planilhas e computadas em termos de escores, sendo então submetidas a análises estatísticas descritivas e inferenciais no Programa SPSS for Windows. Os depoimentos dos participantes, obtidos por vídeo-gravação, foram analisados tão somente como forma de selecionar relatos ilustrativos de mudança sobre: (a) comportamentos do filho, alvos do programa de intervenção; (b) comportamentos dos pais; (c) práticas educativas; (d) comportamentos observados por outros significantes.

\section{Resultados}

A assiduidade do grupo a cada um dos encontros/passos do programa de intervenção é apresentada na Figura 1.

Como se vê, a assiduidade situou-se acima de $80 \%$ na maioria dos encontros, sendo que apenas nos passos 4 e 7 as taxas de presença foram iguais ou inferiores a 50\%. Esse dado é importante porque sugere que as condições motivacionais (intrínsecas ou extrínsecas) estabelecidas pelo programa foram relativamente efetivas.

Para a análise da eficácia do programa foram utilizados os resultados de 32 pais da amostra, já que dois deles

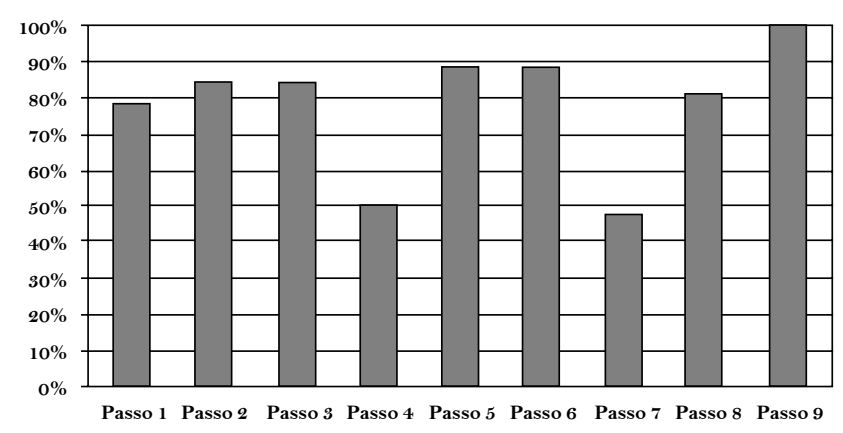

Figura 1. Percentagem de pais presentes em cada um dos encontros/ passos do programa de intervenção. concluíram o programa mas não preencheram o questionário pós-treinamento.

Os resultados do Inventário de Comportamentos Inoportunos indicaram uma queda acentuada na média: no prétreino era de $32,22(\mathrm{dp}=19,183)$ e caiu para 24,03 $(\mathrm{dp}=14,252)$ no pós-treino. O mesmo ocorreu com os resultados do Questionário de Situações Domésticas: a média de situações pré-intervenção era de $7,63(\mathrm{dp}=3,705)$ e caiu para $5,56(\mathrm{dp}=3,311)$. A severidade das situações no prétreino era de $5,40(\mathrm{dp}=1,884)$ e caiu para $4,35(\mathrm{dp}=1,894)$ na avaliação final. Todos esses resultados se mostraram estatisticamente significativos conforme se observa na Tabela 1.

Uma estimativa dos efeitos do treinamento foi obtida por meio do método proposto por Kazis, Anderson e Meenan(1989). A estimativa utilizada para avaliar os efeitos consiste em calcular as diferenças nas médias dos escores entre o pós-treino e o pré-treino, dividindo esse número pelo desvio-padrão dos escores no pré-treino. Os resultados obtidos com o Inventário de Comportamentos Inoportunos e o Questionário de Situações Domésticas indicaram que os efeitos do programa foram de intensidade moderada, da ordem 0.5 (ver, por exemplo, Sharrack, Hughes, Soudain \& Dunn, 1999, p. 144).

As entrevistas, conduzidas após o encerramento de cada grupo, permitiu obter indicadores qualitativos sobre os efeitos do programa. Nessa avaliação, verificou-se que algumas das atividades realizadas nas sessões de treinamento foram elaboradas ou adaptadas pelos pais e aplicadas nas situações domésticas, com relato dos pais indicando adequação do uso de procedimentos para a solução de problemas nas situações singulares de cada família.

Nos depoimentos apresentados pelos pais ao final do programa (todos valorizando os resultados obtidos), identificou-se relatos ilustrativos de mudanças na qualidade do seu relacionamento com os filhos e melhora nos comportamentos das crianças. Alguns desses depoimentos são apresentados a seguir:

Eu aprendi a conversar melhor com meu filho.

Eu aprendi a dar mais atenção ao meu filho.

Antes eu já não batia, hoje percebo que a qualidade melhorou.

Eu era muito nervosa, muito estressada para lidar com o 'João'.

Agora ele me ouve mais.

Ele melhorou muito em casa até para fazer o trabalho de casa. Eu aprendi a ter um tempo para brincar com ele.

Eu aprendi a entender a curiosidade dele.

Até minha família tem falado que ele melhorou muito de comportamento.

As experiências diferentes de outros pais são importantes. A gente aprende vendo os outros.

Tabela 1

Dados Descritivos e Inferenciais dos Resultados Obtidos no Comportamento das Crianças, conforme Avaliação feita pelos Pais

\begin{tabular}{|c|c|c|c|c|c|c|c|}
\hline \multirow[t]{2}{*}{ Aspectos Avaliados } & \multicolumn{2}{|c|}{ Pré-Treino } & \multicolumn{2}{|c|}{ Pós-Treino } & \multirow{2}{*}{$\mathrm{t}$} & \multirow{2}{*}{ gl } & \multirow{2}{*}{$\mathrm{p}$} \\
\hline & Média & DP & Média & $\mathrm{DP}$ & & & \\
\hline Freqüência de Comportamentos Inoportunos & 32,22 & 19,183 & 24,03 & 14,252 & 3,222 & 31 & 0,003 \\
\hline $\mathrm{N} .^{\circ}$ de situações domésticas problemáticas & 7,63 & 3,705 & 5,56 & 3,311 & 3,535 & 32 & 0,001 \\
\hline Severidade dos comportamentos problemáticos & 5,40 & 1,884 & 4,35 & 1,894 & 2,874 & 31 & 0,007 \\
\hline
\end{tabular}




\section{Discussão}

A análise dos resultados qualitativos e quantitativos deste estudo indicou que essa proposta de programa para ampliar o repertório de habilidades sociais educativas dos pais de crianças em situação de risco foi bem sucedida, observando-se melhoras significativas nos comportamentos inadequados das crianças e ainda mudanças consideráveis nas interações intrafamiliares.

Esses resultados confirmam algumas expectativas quanto ao repertório de habilidades sociais educativas das famílias em situação de risco como as que participaram da presente intervenção. Os dados de depoimentos, colhidos durante os passos, apontaram dificuldades rotineiras ou eventuais no desempenho social da maioria dos participantes. Por outro lado, as verbalizações de dúvidas dos pais sobre a forma de educar suas crianças ocorreram com bastante freqüência durante o programa. A grande maioria dos pais entendia que devia adotar uma postura rígida em relação às respostas inadequadas dos filhos, e que, caso não os castigassem fisicamente, estariam sendo omissos ou permissivos com a ação desobediente. Os resultados indicam que os pais não somente modificaram seus comportamentos mas, também, foram positivamente reforçados com essa mudança, ao constatarem alterações nos comportamentos de seus filhos. Este estudo faz parte de um programa maior de pesquisa, cuja continuidade prevê a comparação da forma atual do TP-HS com outras modalidades de intervenção.

Algumas limitações do estudo precisam ser aqui consideradas. A ausência de um grupo controle restringiu a pesquisa a um delineamento do tipo $\mathrm{AB}$, com comparações do intra-grupo, tendo como base o uso de medidas repetidas antes e após o treino. Essa natureza pré-experimental do estudo não permite fazer inferências válidas quanto à especificidade dos seus efeitos no sentido de verificar ultrapassarem os benefícios da mera troca de experiências sobre dificuldades de educar os filhos, recebimento de atenção ou oportunidade de discutir e receber orientações. Uma outra limitação do presente estudo foi a não realização de seguimento (follow-up) para avaliar a permanência, no tempo, dos possíveis ganhos obtidos. Adicionalmente investigações mais detalhadas se fazem necessárias quanto à fidedignidade e estabilidade dos escores nos questionários (adaptados) na ausência de quaisquer intervenções, de forma a poder estimar, com maior precisão, a magnitude dos efeitos obtidos em relação a eventuais efeitos de re-testagem.

Além das considerações metodológicas referidas, o presente estudo focalizou somente uma das fontes de fatores associados a problemas de comportamento de crianças, as habilidades dos pais no manejo de tais comportamentos e na promoção de comportamentos alternativos. Considerando-se o caráter multideterminante dos problemas de comportamento na infância, pode-se destacar a necessidade de novos estudos focalizando, concomitantemente à intervenção junto aos pais, os efeitos de uma intervenção junto à escola, professores e pares, ou, pelo menos, a avaliação junto a esses segmentos.
Não obstante as limitações referidas, é importante ressaltar as dificuldades logísticas envolvidas no planejamento e execução de programas de intervenção com pais, a escassez de recursos materiais para financiar empreendimentos dessa natureza, as dificuldades de obter apoio institucional e de acesso a comunidades que vivem em regiões urbanas virtualmente conflagradas no Brasil contemporâneo. Sob tais condições, os resultados, apesar de incipientes, são animadores no sentido de indicarem que, face às reservas expressas quanto à eficácia e indicação de programas de treinamento de pais na presença de adversidade social (por exemplo, Barkley, 1997), tais contra-indicações devem ser relativizadas.

A julgar pela assiduidade e pelos resultados das entrevistas e inventários, o programa foi bem aceito pelos participantes, revelando, portanto validade social. As famílias também não tiveram dificuldades em citar espontaneamente situações da vida cotidiana para as quais estavam generalizando as novas habilidades e conceitos adquiridos. A implementação da intervenção pelos pais, no ambiente da criança e da família, era justamente um dos objetivos do trabalho colaborativo entre terapeuta e família neste modelo de treinamento de pais. A generalização relatada sugere que os indivíduos assimilaram os princípios do programa e estavam fazendo uso do mesmo no contex to das suas vidas.

\section{Referências}

Barkley, R. A., (1997). Defiant children: A clinician's manual for assessment and parent training (2nd. ed.). New York: Guilford.

Baumrind, D. (1996). The discipline controversy revisited. Family Relations, 45, 405-414.

Becvar, D. S., \& Becvar, R. J. (1999). Family therapy: A systemic integration (4nd. ed.) Boston: Allyn \& Bacon.

Bolsoni-Silva, A. T., Del Prette, A., \& Oishi, J., (2003). Habilidades sociais de pais e problemas de comportamento dos filhos. Psicologia: Argumento, 9, 11-29.

Collins, W. A., Maccoby, E. E., Steinberg, L., Hetherrington, E. M., \& Bornstein, M. H. (2000). Contemporary research on parenting. The case for nature and nurture. American Psychologist, 55, $218-232$.

Costa, E. T., Teixeira, M. A. P., \& Gomes, W. B. (2000). Responsividade e exigência: Duas escalas para avaliar estilos parentais. Psicologia: Reflexão e Crítica, 13, 465-473.

Del Prette, A., \& Del Prette Z. A. P. (2001). Psicologia das relaçôes interpessoais: Vivências para o trabalho em grupo. Petrópolis, RJ Vozes.

Del Prette, A., \& Del Prette, Z. A. P. (2003). Aprendizagem socioemocional na infância e prevenção da violência: Questões conceituais e metodologia da intervenção. In A. Del Prette A. \& Z. A. P. Del Prette (Eds.), Habilidades sociais, desenvolvimento e aprendizagem (pp. 83-127). Campinas, SP: Alínea.

Del Prette, Z. A. P., \& Del Prette, A. (1999). Psicologia das habilidades sociais: Terapia e educação. Petrópolis, RJ: Vozes.

Del Prette, Z. A. P., \& Del Prette, A. (2005). Psicologia das habilidades sociais na infância: Terapia e educação: Petrópolis, RJ: Vozes.

Gomide, P. I. C. (2003). Estilos parentais e comportamentos antisociais. In A. Del Prette \& Z. A. P. Del Prette (Eds.) Habilidades sociais, desenvolvimento e aprendizagem: Questões conceituais, avaliação e intervenção (pp. 21-60). Campinas, SP: Alínea. 
Dodge, K. A. (1993). Social cognitive mechanisms in the development of conduct disorder and depression. Annual Review of Psychology, 44, 559-84.

Dodge, K. A., Bates, J. E., \& Pettit, G. S. (1990). Mechanisms in the cycle of violence. Science, 250, 1678-83.

Haase, V. G., Freitas, P. M. de, Natale, L. L., \& Pinheiro, M. I. S. (2002). Treinamento comportamental de pais: Uma modalidade de intervenção em neuropsicologia do desenvolvimento. In A. M. S. Teixeira, M. R. B. Assunção, R. R. Starling \& S. S. Castanheira (Eds.), Ciência do comportamento. Vol. 1. Conhecer e avançar (pp. 73-89). Santo André, SP: Esetec.

Haase, V. G., Käppler, C., \& Schaefer, A. S. (2000). Um modelo de Intervenção psicoeducacional para prevenção da violência no ambiente familiar e escolar psicologia do desenvolvimento. In V. G. Haase, R. Rothe-Neves, C. Käppler, M. L. M. Teodoro, \& G. M. O. Wood (Eds.), Psicologia do desenvolvimento: Contribuições interdisciplinares (pp. 265-282). Belo Horizonte, MG: Health.

Käppler, C., Schaefer, A., Lourenço, C. A. P., Heleno, C. T., Freitas, P. C., Dagnoni, J. M., Bonvicini, C. R., Miranda, M. S., \& Haase, V. G. (2003). Gewaltprävention in Familien mit psychosozialen Risiken: ein adaptiertes Trainingsprogramm für Elterngruppen in Armenvierteln von Brasilien. In U. Lehmkuhl (Ed.), Aggressives Verhalten bei Kindern und Jugendlichen. Ursachen, Prävention, Behandlung (pp. 183-190). Göttingen, Germany: Vandenhoeck \& Ruprecht.

Kazis E. L., Anderson J. J., \& Meenan, R. F. (1989). Effect sizes for interpreting changes in health status. Medical Care, 27 (Suppl. 3), 178-189.

Loeber, R., \& Hay, D. (1997). Key issues in the development of aggression and violence from childhood to early adulthood. Annual Review of Psychology, 48, 371-410.

McMahon, R. J. (1999). Treinamento de pais. In V. E. Caballo (Ed.), Manual de técnicas de terapia e modificação do comportamento (pp. 399-422). São Paulo, SP: Santos.

Nichols, M. P., \& Schwartz, R. C. (1998). Family therapy. Concepts and methods (4nd. ed.). Boston: Allyn \& Bacon.
Oliveira, E. A. de, Marin, A. H., Pires, F. B., Frizzy, G. B., Ravanello, T., \& Rossatto, C. (2002). Estilos parentais autoritário e demorcrático-recíproco intergeracionais: Conflito conjugal e comportamentos de externalização e internalização. Psicologia: Reflexão e Crítica, 15, 1-14.

Patterson, G. R. (1986). Performance models for antisocial boys, American Psychologist, 41, 432-444.

Patterson, G. R., DeBaryshe, B. D., \& Ramsey, E. (1989). A developmental perspective on anti-social behavior. American Psychologist, 44, 329-335.

Patterson, G. R., Reid, J. B., \& Dishion, T. J. (1992). Antisocial boys. Eugene, OR: Castalia.

Petermann, F., \& Petermann, U. (1997). Training mit aggressiven Kindern, inzeltraining, kindergrouppe, elternberatung (8. ed.). Weinheim, Germany: Beltz.

Pinheiro, M. I. S., Del Prette, A., \& Haase, V. G., (2002). Pais como co-terapeutas: Treinamento em habilidades sociais como recurso adicional (Relatório Técnico Vol. 3, No. 1, pp. 1-42). Belo Horizonte, MG: Universidade Federal de Minas Gerais, Departamento de Psicologia, Laboratório de Neuropsicologia do Desenvolvimento e Laboratório de Psicologia da Família.

Rutter, M. J. (1997). Nature-nurture integration. The example of antisocial behavior, American Psychologist, 52, 390-398.

Sharrack, B., Hughes, R. A., Soudain, S., \& Dunn, G. (1999). The psychometric properties of clinical rating scales used in multiple sclerosis. Brain, 122, 141-159.

Simons, R. L., Chão, W., Conger, R. D., \& Elder, G. (2001). Quality of parenting as mediator of the effect of childhood deficiency on adolescent friendship choices and delinquency: A growth curve analysis. Journal of Marriage and Family, 63, 63-79.

Weber, L. N. D., Prado, P. M., Viezzer, A. P., \& Brandenburg, O. J. (2004). Identificação de estilos parentais: O ponto de vista dos pais e dos filhos. Psicologia: Reflexão e Crítica, 17, 323-331.

Recebido: 02/05/2005 $1^{a}$ revisão: 06/10/2005

$2^{a}$ revisão: 30/01/2006 Aceite final: 23/03/2006 